\title{
Periodontal Disease of Pregnant Women and Low Weight Newborn in Senegal: A Case-Control Study
}

\author{
D. Cisse1, M. Diouf ${ }^{1}$, A. Faye ${ }^{2}$, M. F. Diadhiou ${ }^{3}$, A. Tal-Dia ${ }^{2}$ \\ ${ }^{1}$ Service de Santé Publique Dentaire, Département d'Odontologie, Université Cheikh Anta Diop, Dakar, Sénégal \\ ${ }^{2}$ Service de Santé Publique et Médecine Préventive, Université Cheikh Anta Diop, Dakar, Sénégal \\ ${ }^{3}$ Service de Gynécologie Obstétrique, Hôpital Le Dantec, Dakar, Sénégal \\ Email: dioufmass78@yahoo.fr
}

Received 20 December 2014; accepted 13 January 2015; published 20 January 2015

Copyright (C) 2015 by authors and Scientific Research Publishing Inc.

This work is licensed under the Creative Commons Attribution International License (CC BY).

http://creativecommons.org/licenses/by/4.0/

c) (i) Open Access

\begin{abstract}
The aim of this work was to study the connection between periodontal diseas of women during their pregnancy and the weight of newborn infants the women gave birth to. Method: It was a case-control study and carried out on the outskirts of Dakar (Senegal). The sample consisted of 129 mothers with infants of weight $<2500 \mathrm{~g}$ (case) and 258 mothers with infants of weight $\geq 2500$ $\mathrm{g}$ (control). The socio-demographic variables, patterns of life, history and outcome of pregnancy were collected. The variables relating to periodontal status included the plaque index, inflammation, bleeding, loss of clinical attachment and pocket depth. Data were analyzed by the $R$ software. Logistic regression had identified associations on the threshold of $5 \%$. Results: The proportions of mothers with periodontitis were $\mathbf{7 0 . 6 \%}$ among cases versus $33 \%$ in controls. Periodontitis was significantly associated with low weight (OR $=4[2.3-5.7] 4)$ adjusted on age, BMI and other periodontal indices. Conclusion: periodontal disease appears to be involved in the occurrence of low birth weight in the African context. The introduction of an oral component in prenatal consultations is therefore necessary for the health of mothers and their children.
\end{abstract}

\section{Keywords}

Periodontal Disease, Pregnant Women, Low Birth Weight, Senegal

\section{Introduction}

In Senegal, over the last 15 years, unlike the infant mortality rate juvenile who declined, the rate of neonatal 
mortality has not registered a significant decrease. In fact, it went from 40\%o - 27\%o between 1990 and 2010 according to demographic and health surveys (DHS). This rate is even higher in rural than urban areas (42.9\%o versus 34.4\%) [1] [2]. As in all developing countries, the causes of neonatal mortality are mainly related to infections, low weight and/or prematurity among others. However, the low weight is very prevalent in Africa [3][6]. According to the EDS III [1] survey, $13.5 \%$ of women on average give birth to a newborn weighing less than 2500 g. The prevalence reported by Camara et al. [5] in Dakar was over 10\%. Periodontal diseases, which are inflammatory and polymicrobial disorders are characterized by their magnitude and gravity. Epidemiological data in the world, have reported a prevalence of $80 \%$ for gingivitis and less than $30 \%$ for periodontitis [7]. Several risk factors have been implicated [4] [5]. However, Barnett et al. [8] found that 25\% of low birth weight or premature occur without known risk factors. In Senegal, Sembene et al. in 2000 [6], found through a cross-sectional descriptive study that women with a need for periodontal treatment were more likely to have children of low weight without determining an association. The objective of this study was to investigate the association between periodontal disease in the mother and the baby's weight at birth.

\section{Materials and Methods}

\subsection{Area and Type of Study}

The Department of Guediawaye covers with which of Pikine, the most populous Senegal geographic territory with an average density of over 3600 people per square kilometer. The health center, which is our study area records 500 to 600 deliveries per month. The morbidity and mortality rate is $21 \%$. Given the frequency of low birth weight in this area, a so-called "Kangaroo" unit was established for the early management of these babies. The present case-control study was conducted at the health center Roi Baudouin of Guediawaye.

\subsection{Study Population}

The study population involved all new mothers who gave birth at the health center with their newborns.

\subsection{Inclusion Criteria}

The cases were made by mothers whose babies weight at birth $<2500 \mathrm{~g}$. Controls represented mothers with newborn birth weight $\geq 2500$ g.

\subsection{Exclusion Criteria}

Mothers who had a gynecological infection during pregnancy or those giving birth to babies with a malformation or are stillborn and those giving birth twins were not taken into account. Mothers giving birth at home and came to the structure for secondary care or those whose health does not allow for an oral clinical examination were also not selected.

\subsection{Recruitment Method}

Cases were recruited sequentially according to their order of arrival. For the controls which were most common, they were drawn at the same time in the population of women in labor motherhood. Matching sex of the newborn was done. Thus for every male newborn from cases were matched two male newborns from controls women. Similarly, for each female newborn from case were matched two female newborns from controls.

\subsection{Sample Size}

The sample size was calculated using the Epi 2000. Considering a risk of 5\% with a power of $80 \%$ with reference to the work of Diallo et al. [9], we made a theoretical exposure of $32 \%$ for periodontal disease controls. A $1.9 \%$ risk of delivering a low birth weight child when the mother has periodontitis was fixed arbitrarily. The final sample size was then 258 controls and 129 cases or 1 case for 2 controls.

\subsection{Ethical Considerations}

Before administering the questionnaire, we explained the purpose and importance of the survey to patients for 
their consent; motivation and hygiene education were offered to them after the investigation.

\subsection{Data Collection}

Data were collected using a questionnaire. The questionnaire was pre-tested on 10 patients attending the maternity health post in the same neighborhood. The collection took place every day and involved all patients come to give birth at the maternity clinic and who met the selection criteria. It took place from February to May, 2010.

The information collected included: socio-demographic and biological characteristics: age, parity, body mass index (BMI), income, inbreeding; lifestyle: smoking, coffee, tea; medical history: anemia, hypertension, diabetes, malaria; data on pregnancy: mode of delivery, pre-eclampsia; periodontal data: periodontitis, plaque index, gingival index, papillary bleeding index, probing depth, attachment loss. Twenty-four hours after delivery, the mother was invited to an interview complemented by a clinical examination.

\subsection{Exposure Measuring}

It covered all the independent variables, which is the main, periodontitis was defined in any parturient with a loss of clinical attachment at least equal to $3 \mathrm{~mm}$ in at least 2 sites and a pocket depth $\geq 4 \mathrm{~mm}$ [10] [11]. A full review tray with a graduated periodontal probe was used to perform periodontal measures. This review was done by a student thesis year of dental surgery. He was previously standardized for these types of measures. Only the incisors and first molars, maxillary and mandibular were taken into account for the clinical examination. L'évaluation du niveau d'hygiène était faite par l'indice de plaque (PII) de Silness et Löe (1964) [11]. The gingival condition was assessed by the gingival index (GI) of Löe (1967) [11]. The degree of bleeding was determined by the Saxer and Muhlemann papillary bleeding index (PBI) [11]. Periodontal probing for the determination of clinical attachment loss (CAP) and pocket depth (PD) measurements were performed with three labial measurements (mesiolabial, midlabial and distallabial) and three lingual or palatal ones.

\subsection{Measure of Outcome or Dependent Variable}

Measuring the outcome (birth weight) was with a baby scale. This balance was brand Kern MBE 10K10 version 1.0. The measurements were made by the mistress midwife.

\subsection{Strategy for Data Analysis}

Data entry was performed with Epi 2000 software version 5.3.1. Univariate analysis provided the proportions and the mean or median of the variables studied. Certain variables were redefined in dichotomized yes and no. Associations between variables were examined by the chi2 test or its variants (Fisher and Yates) and their strengths were determined by odds ratios with confidence intervals. Modeling with backward manual procedure (backward selection) was developed with variables whose p was less than 0.25 in bivariate analysis between an independent variable and the dependent variable. At each step, the variable associated with the largest p-value was removed from the model at $5 \%$. The procedure is stopped when all of the remaining variables in the model all had a p-value less than the threshold with the exception of those forced (periodontitis, age and BMI). To control the confusion, we checked at each output variable, the change in odds ratio of the primary independent variable "periodontitis" by calculating the relative change. Interactions with the variable "periodontitis" were tested. The R version 2.9.0 software was used. This analysis strategy was used to identify independent variables significantly associated with the dependent variable (low weight). The results were marginally significant when close to $5 \%$ and significant $\mathrm{p}$ where $\mathrm{p}$ was less than $5 \%$. In the subsample of mothers giving low infant birth weight, three have not had a periodontal clinical examination for health reasons. For the controls, there were six for the same reasons. These mothers have not participated to the study and finally, the size was 126 cases versus 252 controls.

\section{Results}

\subsection{Description of Socio-Demographic and Biological Characteristics, Lifestyle, Medical History and Pregnancy Outcome}

Table 1 shows that the "age”, "BMI” and "vaginal delivery" were significantly associated with low infant 
Table 1. Odds ratios of the various characteristics of mothers associated with low infant birth weight by simple logistic regression.

\begin{tabular}{|c|c|c|c|c|c|c|}
\hline Characteristics (units) & Modalities & Case $n=126$ & Controls n’ $=252$ & OR & IC $95 \%$ & P-value \\
\hline \multicolumn{7}{|c|}{ Socio-demographic and biological characteristics of mothers } \\
\hline Age of mother (year) & & 126 & 252 & 1.68 & {$[1.14-2.01]$} & 0.046 \\
\hline Parity & - & 126 & 252 & 0.86 & {$[0.72-1.03]$} & 0.11 \\
\hline $\mathrm{BMI}\left(\mathrm{Kg} / \mathrm{m}^{2}\right)$ & & 126 & 252 & 2.05 & {$[1.29-2.74]$} & 0.01 \\
\hline \multirow{2}{*}{ Income (FCFA) } & $\geq 100000$ & 21 & 36 & 1.2 & {$[0.64-2.24]$} & 0.54 \\
\hline & $<100000$ & 105 & 216 & 1 & - & - \\
\hline \multirow{2}{*}{ inbreeding } & Yes & $12(9.5 \%)$ & $17(6.7 \%)$ & 1.46 & [0.63 - 3.34] & 0.33 \\
\hline & No & 114 & 235 & & & \\
\hline \multicolumn{7}{|c|}{ Lifestyle of mothers } \\
\hline \multirow{2}{*}{ Active tobacco } & Yes & $3(0.2 \%)$ & $4(1.5 \%)$ & 1.51 & [0.26 - 8.13] & 0.59 \\
\hline & No & 123 & 248 & 1 & - & - \\
\hline \multirow{2}{*}{ Passive smoking } & Yes & $17(13 \%)$ & $31(12 \%)$ & 1.51 & [0.56 - 2.19] & 0.74 \\
\hline & No & 108 & 219 & 1 & - & - \\
\hline \multirow{2}{*}{ Coffee } & Yes & 38 (30\%) & 77 (30\%) & 0.88 & {$[0.60-1.60]$} & 0.94 \\
\hline & No & 88 & 175 & 1 & - & - \\
\hline \multirow{2}{*}{ Tea } & Yes & 63 (49\%) & $115(45 \%)$ & 1.19 & [0.76 - 1.87] & 0.42 \\
\hline & No & 63 & 137 & 1 & - & - \\
\hline \multicolumn{7}{|c|}{ Medical history } \\
\hline \multirow{3}{*}{ Anemia } & Yes & $65(52 \%)$ & 115 (5.6\%) & 1.27 & [0.81 - 1.99] & 0.27 \\
\hline & No & 61 & 137 & 1 & - & - \\
\hline & Yes & 12 (9.5\%) & $14(5.5 \%)$ & 1.77 & {$[0.74-4.23]$} & 0.16 \\
\hline Diabetes & No & 114 & 236 & 1 & - & - \\
\hline \multirow{2}{*}{ Hypertension } & Yes & $28(22 \%)$ & $36(14.2 \%)$ & 1.71 & [0.96 - 3.07] & 0.052 \\
\hline & No & 98 & 216 & 1 & - & - \\
\hline \multirow[b]{2}{*}{ Malaria } & Yes & 49 (39\%) & 83 (33\%) & 1.29 & {$[0.81-2.06]$} & 0.26 \\
\hline & No & 77 & 168 & 1 & - & - \\
\hline \multicolumn{7}{|c|}{ Pregnancy outcome } \\
\hline \multirow{2}{*}{ Mode of delivery } & Vaginal & 89 (71\%) & 151 & 1.61 & [0.99 - 2.61] & 0.042 \\
\hline & Cesarean & 37 & 101 & 1 & - & - \\
\hline \multirow{2}{*}{ Pre-eclampsia } & Yes & $6(4.7 \%)$ & $3(1.2 \%)$ & 4.45 & [0.90 - 21.3] & 0.07 \\
\hline & No & 120 & 250 & & & \\
\hline
\end{tabular}

${ }^{*} 655.957=1 €$.

birth weight in bivariate analysis.

\subsection{Description of Periodontal Characteristics}

Table 2 describes the associations between periodontal characteristics of the mother and baby low birth weight in simple logistic regression. All these characteristics were associated with baby low birth weight.

Table 3 presents the final model retained after multivariate analysis using the manual procedure down. It showed that periodontitis in mothers was significantly associated with baby low birth weight ( $\mathrm{OR}=4.4$ [ 2.3 to 5.7]) adjusted for age, BMI and other variables. The age of the mother and plaque index were marginally associated with baby low birth weight $(\mathrm{p}=0.05$ and 0.053$)$ while BMI, gingival index and papillary bleeding were 
Table 2. Odds ratios of periodontal characteristics of mothers associated with baby low birth weight by simple logistic regression.

\begin{tabular}{|c|c|c|c|c|c|c|}
\hline $\begin{array}{l}\text { Periodontal characteristics } \\
\text { (units) }\end{array}$ & Modalities & $\begin{array}{c}\text { Case } \\
\mathrm{N}=126\end{array}$ & $\begin{array}{l}\text { Controls } \\
\mathrm{N}=252\end{array}$ & OR & CI & p-value \\
\hline \multirow{2}{*}{ Periodontitis } & Yes & $89(70 \%)$ & 83 (33\%) & 4.9 & {$[3.1-7.8]$} & $<0.001$ \\
\hline & No & 37 & 169 & 1 & - & - \\
\hline Plaque index & & 126 & 252 & 2.016 & {$[1.01-3.02]$} & 0.047 \\
\hline Gingival index & & 126 & 252 & 3.022 & {$[1.18-4.03]$} & 0.026 \\
\hline Bleeding index & & 126 & 252 & 4.019 & {$[2.01-6.02]$} & $<0.001$ \\
\hline Attachment loss (mm) & & 126 & 252 & 2.1 & {$[1.1-3.7]$} & 0.044 \\
\hline Pocket depth (mm) & & 126 & 252 & 2.045 & {$[1.35-4.55]$} & 0.049 \\
\hline
\end{tabular}

Table 3. Odds ratio of the mothers characteristics associated with baby low birth weight in multivariate regression hand down.

\begin{tabular}{|c|c|c|c|c|}
\hline \multicolumn{2}{|c|}{ Characteristics modalities } & \multirow{2}{*}{$\begin{array}{c}\text { OR } \\
4.45\end{array}$} & \multirow{2}{*}{$\begin{array}{c}\text { CI 95\% } \\
{[2.3-5.7]}\end{array}$} & \multirow{2}{*}{$\begin{array}{l}\text { P-value } \\
0.00013\end{array}$} \\
\hline Dorindontitic & Yes & & & \\
\hline Pentodontus & No & 1 & - & - \\
\hline \multicolumn{2}{|c|}{ Age of mother } & 1.62 & [0.99 - 2.02] & 0.05 \\
\hline \multicolumn{2}{|c|}{ BMI } & 2.03 & [1.21 - 3.05] & 0.03 \\
\hline \multicolumn{2}{|c|}{ Plaque index } & 1.89 & {$[0.99-2.01]$} & 0.053 \\
\hline \multicolumn{2}{|c|}{ Gingival index } & 2.015 & [1.11 - 3.022] & 0.026 \\
\hline \multicolumn{2}{|c|}{ Bleeding index } & 3.1 & {$[2.04-6.05]$} & 0.015 \\
\hline \multicolumn{2}{|c|}{ Attachment loss (mm) } & 2.21 & {$[1.62-4.04]$} & 0.045 \\
\hline \multicolumn{2}{|c|}{ Pocket depth (mm) } & 2.25 & {$[1.23-3.7]$} & 0.041 \\
\hline
\end{tabular}

significantly associated with baby low birth weight $(\mathrm{OR}=2.03$ [1.21, 3.05] 2.015 [1.11 to 3.022], 3.1 [2.04 to 6.05]).

In addition, the terms of assumed interaction (periodontitis $\times$ age $\times$ active periodontitis tobacco $\times$ Passive smoking periodontitis) tested were not significant with $\mathrm{p}=0.89 ; \mathrm{p}=0.56$ and $\mathrm{p}=0.81$.

\section{Discussion}

This work allowed us to study the association between periodontal status of the mother and baby low birth weight. The risk of having a baby low birth weight was 4.45 times higher if the mother had periodontitis with adjustment for age, BMI and other periodontal index.

\subsection{Limitations of the Study}

In calculating the sample size, the choice with reference to the data in the study of Diallo et al. [9], could affect our results because they had not found the prevalence among pregnant women but in the general population. To minimize bias and increase the validity of our results, it was necessary to control for confounding factors known to the baby low birth weight. In addition mothers with gynecological disorder or an infection other than periodontal were not included in the study. However, to reduce residual confounding in the analysis, we adjusted for other factors that are socio-demographic, biological, lifestyle or medical history. When collecting data only one person conducted blind measurement of exposure. As to the outcome or result, it was collected by the midwife and for this, to minimize non-differential misclassification.

\subsection{Socio-Demographic and Biological Characteristics}

The age of the mother include young age ( $<18$ years) may influence the intrauterine growth of the fetus [12]. In our study the average age of cases mothers was lower than that of controls. This age was significantly related to 
baby low birth weight (Table 1). However, this association remained marginal after adjustment for BMI and periodontal characteristics (Table 3). In this study, mothers of low birth weight babies had an average BMI of $25.9 \pm 7.11$ (Table 1). BMI was significantly related to low birth weight baby, even after adjusting for age and periodontal characteristics (Table 3). The case-control study by Ndiaye et al. in 2006 [4] in Senegal did not demonstrate a relationship between BMI and low weight. Parity was not related to infant low birth weight unlike retrospective study of Bobossi-Seringbe [13] in Centrafrique found a statistically significant association ( $\mathrm{p}=$ 0.01). This association could be explained by the lack of adjustment for factors that were not collected due to the retrospective nature of the study. Regarding income couples, it was usually less than 100,000 fcfa (152.4€) per month (Table 1). This is reinforced by the living conditions in the suburbs of Dakar where poverty is relatively common [1]. Our results did not show statistically significant link between income and low baby weight (Table 1) in contrast to those of Camara et al. [5].

\subsection{Lifestyle of Mothers}

In our study, neither passive nor active tobacco smoking were significantly associated with low birth weight baby. These results are similar to those of Ndiaye et al. [4].

The consumption of coffee and tea were not significantly associated with infant low birth weight (Table 1). Bichalo et al. [14] in a case-control study of 354 infants of less than $2500 \mathrm{~g}$ weight and 354 others over $3000 \mathrm{~g}$ showed a lack of statistically significant link between regular tea consumption and the delay of expected growth for a low birth weight baby.

\subsection{Medical History and Pregnancy Outcome}

Anemia was more frequent among cases (Table 1). However, there was no significant association between maternal anemia and infant low birth weight. It was the same for malaria and diabetes (Table 1) whose gestational concerns to $1 \%-4 \%$ of pregnancies according to Reece et al. [15]. The link between hypertension and low weight birth baby was marginally significant $(\mathrm{p}=0.05)$ (Table 1$)$. This pressure, if it is associated with proteinemiaover than $300 \mathrm{mg} /$ day causes preeclampsia formerly called toxemia of pregnancy. Williams et al. [12] in their analysis of the mechanisms of risk of low birth weight baby and /or premature retain these factors as essential. Kramer [16] also ranked among the determinants of the baby's low weight in a meta-analysis study.

\subsection{Periodontal Characteristics}

The effectiveness of plaque control was lower especially in cases (Table 2). However, a qualitative interpretation of the plaque index showed that oral hygiene was deficient in women. The lack of hygiene is probably due to poor brushing technique. Our results showed that the plaque index was significantly related to low birth weight baby in bivariate analysis (Table 2) and that this association was marginal after adjustment for age, BMI and other periodontal characteristics (Table 3). Khader et al. [17] found in that a very significant association relationship ( $<0.001$ ). Inflammations as well as gingival bleeding were lower in controls than in cases (Table 2); the association remained statistically significant even after adjustment for age, BMI and other periodontal characteristics (Table 3). Marin et al. [18] in Brazil on a cross-sectional study of 162 volunteers on the correlation between the child's weight at birth and periodontal status considering only continuous variables, showed that the baby's weight at birth decreased when periodontal status (inflammation and spontaneous bleeding) was more affected (negative correlation). Spontaneous gingival bleeding cannot be responsible for the baby low weight but could be a warning sign or symptom of anemia which would lead the specialist to take adequate preventive measures. However, the presence of a microbial plaque is responsible for inflammation and bleeding factor; this could also encourage reflecting on bacterial translocation [12]. Offenbacher et al. [19] described a series of inflammatory mediators (PGE2, TNF...) involved in the induction of labor to give birth and in greater concentration in an active phase of periodontal disease. However, a case-control study by Isaac et al. [20] in Brazil concluded by a lack of significant association between low birth weight baby and the presence of inflammation and spontaneous bleeding in the mother. The clinical attachment loss and probing pocket depth not averaged $3 \mathrm{~mm}$ both in cases than in controls (Table 2). A comprehensive interpretation of their values does not criminalize the periodontal status in relation to the birth of low weight baby. However, a significant association was obtained after adjustment for age, BMI and other periodontal characteristics (Table 3). Loss of clinical attachment cha- 
racterizes periodontal bone lesion level and is used for the clinical diagnosis of this lesion. Yet these two variables do not interact with periodontitis. It was found that over $70 \%$ of women giving birth to low weight babies had periodontitis versus 33\% for controls (Table 2). These periodontitis allow colonization of the genitourinary tract by gram-negative bacteria. This could cause an immune response after the action of bacterial lipopolysaccharide and the release of pro-inflammatory citokynes [19] which, in turn, can contribute to low birth weight baby or premature birth. The observed association between periodontitis and low birth weight baby was highly significant ( $\mathrm{OR}=4.45$; [2.3 to 5.7]) (Table 3). So the risk of giving birth to a child of low weight was 4.45 times higher when the mother was developing periodontitis. However Buduneli al [21] in Turkey, through case-control study did not reveal any significant relationship between periodontal infections and infant low birth weight and/or prematurity. This lack of relationship may be due to uncontrolled confounding.

\section{Conclusion}

Periodontal disease is associated with the occurrence of low birth weight in the African and Senegalese context. Other etiologic longitudinal studies are needed that highlight the relationship between periodontal disease and low birth weight in black subjects. It is equally important to educate physicians, and more particularly the gynaecologists or midwives, on the need to integrate examination of oral conditions in their consultations.

\section{References}

[1] Ministry of Economy and Finance (1997) Prevention and Statistics Direction/Dakar/Senegal Demographic and Health Survey.

[2] Levels and Trends in Child Mortality. Report 2011 Estimates Developed by the UN Inter-Agency Group for Child Mortality Estimation. 24p.

[3] Keita, M.M., Samake, M. and Dao, A. (1992) The New Born Small Birth Weight in Bamako: Become Immediate. Publication Médicale Africaine, 47, 11-16.

[4] Ndiaye, et al. (2009) Risk Factors Associated with the Small Birth Weight. About a Case Study Witnesses in the Maternity Ward of the Regional Hospital Center of Thies (Senegal). Journal of Neuropsychopharmacology of Child, 19, 153-158.

[5] Camara, B., Diack, B., Diouf, S., Signaté-Sy, H., Sall, M.G., Ba, M., et al. (1996) The Low Birth Weight: Frequency and Risk Factors in the District of Guediawaye (Suburb of Dakar - Senegal). Pub Med. Afr., 45, 260-265.

[6] Sembene, M., Moreau, J.C., Mbaye, M.M., Diallo, A., Diallo, P.D., Ngom, M., et al. (2000) Periodontal Infection of Women in Pregnancy and Low Weight of the Baby at Birth. Odonto-Stomatologie Tropicale, 23, 19-22.

[7] World Health Organization (2004) New Report on the Oral Diseases in the World. WHO, Geneva, 1 p.

[8] Barnett, M.L. (2003) Coordination Meeting on Oral Health and Systemic Health Periodontal Medicine: Health Policy Implication, Geneva Switzerland December 5 and 6 2002. Journal of Periodontology, 73, 1081-1086. http://dx.doi.org/10.1902/jop.2003.74.7.1081

[9] Diallo, P.D., Benoist, H.M., Seck-Diallo, A., Diouf, A. and Sembene, M. (2005) Necrotizing Ulcerative Gingivitis in Senegalese Children: Epidemiolgic Study. Journal de Paradontologie \& d'Implantologie Orale, 24, 169-176.

[10] Sanchez, A.R., Bagniewski, S., Weaver, A.L. and Vallejos, N. (2007) Correlations between Maternal Periodontal Conditions and Preterm Low Birth Weight Infants. Journal of the International Academy of Periodontology, 9, 34-41.

[11] et Tenenbaum, B. (1997) Periodontology from Diagnosis to the Practice. De Boeck \& Larcier, De Boeck, Paris, 289 p.

[12] Williams, C.E., Davenport, E.S., Sterne, J.A., Sivapathasundaram, V., Fearne, J.M. and Curtis, M.A. (2000) Mechanisms of Risk in Preterm or Low Birth Weight Infants. Journal of Periodontology, 23, 142-150.

[13] Bobossi-Serengbe, M., Mbongo-Zindamoyen, A.N., Diemer, H., Nadji-Adim, F. and Siopathis, R.M. (2000) Newborns of Low Birth Weight to the Neonatal Pediatric Complex of Bangui (RCA) Unit: Become Immediate and Prognosis. Publication Médicale Africaine, 47, 191-195.

[14] Bicalho, G.G. and Barros, F.A.A. (2002) Birth Weight and Caffeine Consumption. Revista de Saúde Pública, 36, 180187

[15] Reece, A., Leguigamon, G. and Wiznitzer, A. (2009) Gestational Diabetes: The Need for a Common Ground. The Lancet, 73, 1789-1797. http://dx.doi.org/10.1016/S0140-6736(09)60515-8

[16] Kramer, M.S. (1987) Determinants of Low Birth Weight: Methodological Assessments and Meta-Analysis. Bulletin of the World Health Organization, 65, 663-737.

[17] Khader, Y., Al-shishani, L., Obeidat, B., Khassawneh, M., Burgan, S., Amarin, Z.O., et al. (2009) Maternal Perio- 
dontal Status and Preterm Low Birth Weight Delivery: A Case Control Study. Archives of Gynecology and Obstetrics, 279, 165-169. http://dx.doi.org/10.1007/s00404-008-0696-2

[18] Marin, C., Segura-Egea, J.J., Martinez-Sahuquillo, A. and Bullon, P. (2005) Correlation between Infant Birth Weight and Mother's Periodontal Status. Journal of Clinical Periodontology, 32, 299-304. http://dx.doi.org/10.1111/j.1600-051X.2005.00661.x

[19] Offenbacher, S., Katz, V., Fertik, G., Collins, J., Boyd, D., Maynor, G., Mckaig, R. and Beck, J. (1996) Periodontal Infection as a Possible Risk Factor for Preterm Low Birth Weigt. Journal of Periodontology, 67, 1103-1113. http://dx.doi.org/10.1902/jop.1996.67.10s.1103

[20] Isaac, S. (2006) Periodontal Status as Predictor of Prematurity and Low Birth Weight. Journal of Public Health Dentistry, 66, 295-298. http://dx.doi.org/10.1111/j.1752-7325.2006.tb04088.x

[21] Buduneli, N., Baylas, H., Bubuneli, E., Turkoglu, O., Kose, T. and Dahlen, G. (2005) Periodontal Infections and Preterm Low Birth Weight a Case Control Study. Journal of Clinical Periodontology, 32, 174-181. http://dx.doi.org/10.1111/j.1600-051X.2005.00670.x 
Scientific Research Publishing (SCIRP) is one of the largest Open Access journal publishers. It is currently publishing more than 200 open access, online, peer-reviewed journals covering a wide range of academic disciplines. SCIRP serves the worldwide academic communities and contributes to the progress and application of science with its publication.

Other selected journals from SCIRP are listed as below. Submit your manuscript to us via either submit@scirp.org or Online Submission Portal.
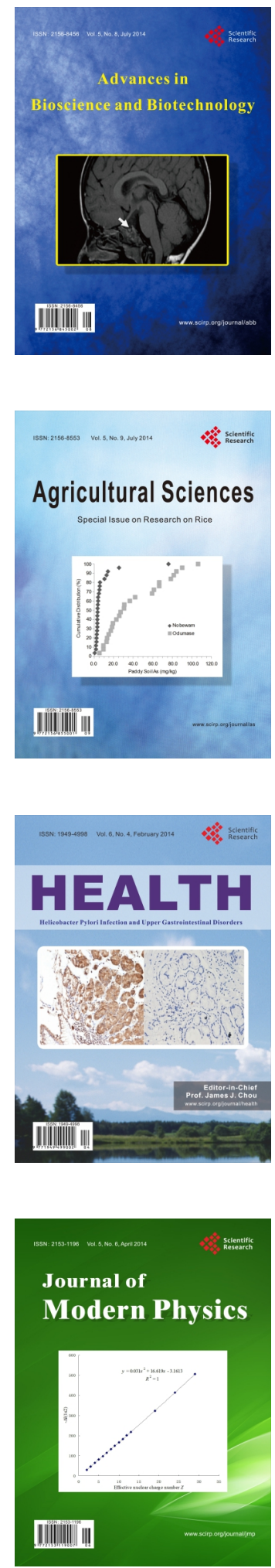
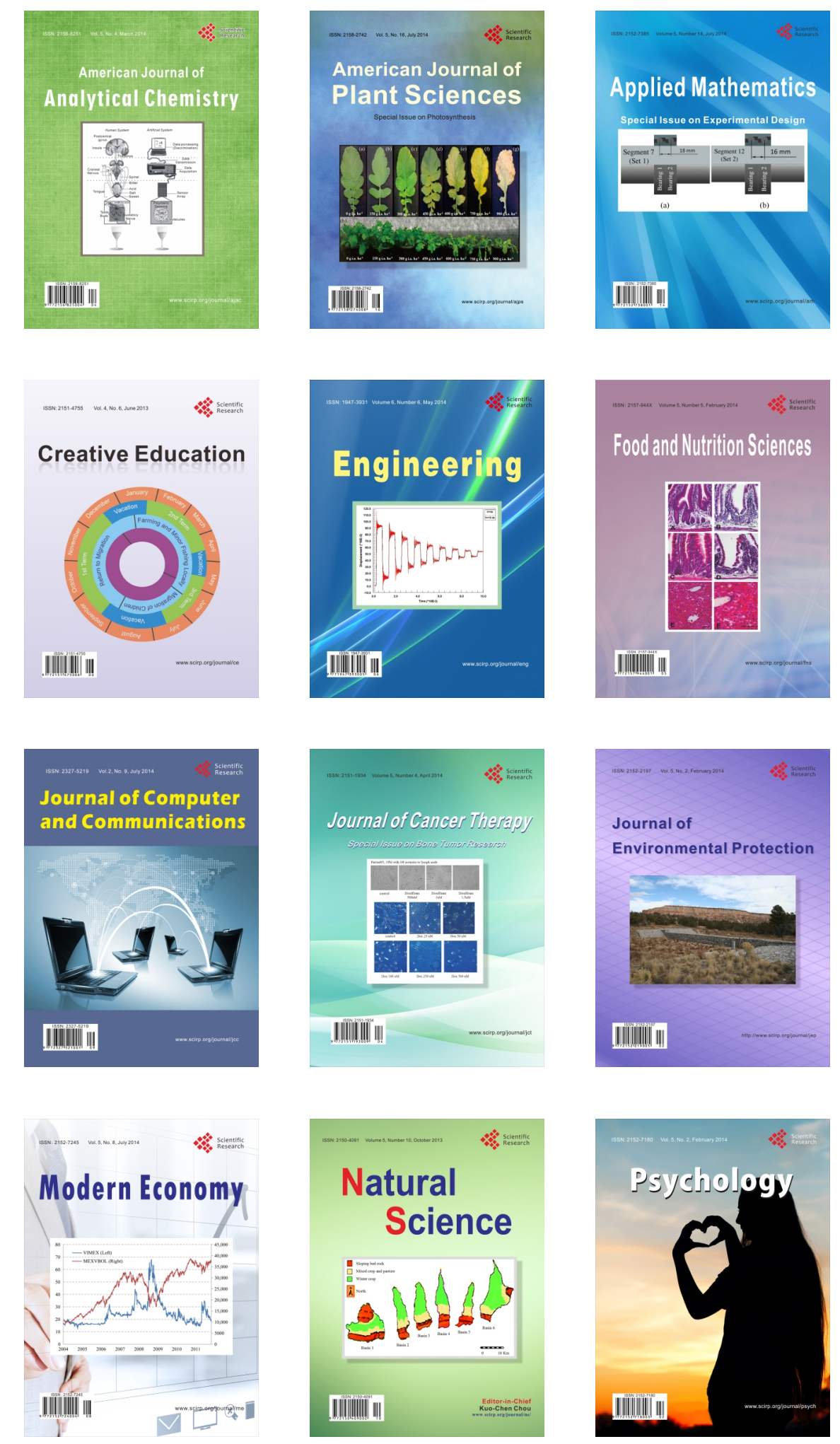